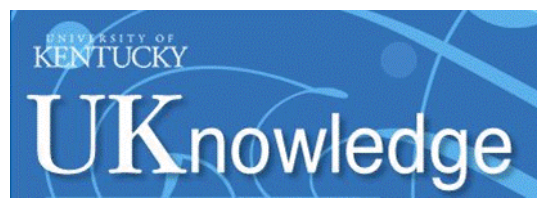

University of Kentucky

UKnowledge

\title{
The Selfie Generation: Examining the Relationship Between Social Media Use and Early Adolescent Body Image
}

\author{
Ilyssa P. Salomon \\ University of Kentucky, ilyssa.salomon@gmail.com \\ Digital Object Identifier: https://doi.org/10.13023/ETD.2017.130
}

Right click to open a feedback form in a new tab to let us know how this document benefits you.

\section{Recommended Citation}

Salomon, llyssa P., "The Selfie Generation: Examining the Relationship Between Social Media Use and Early Adolescent Body Image" (2017). Theses and Dissertations--Psychology. 112.

https://uknowledge.uky.edu/psychology_etds/112

This Master's Thesis is brought to you for free and open access by the Psychology at UKnowledge. It has been accepted for inclusion in Theses and Dissertations--Psychology by an authorized administrator of UKnowledge. For more information, please contact UKnowledge@lsv.uky.edu. 


\section{STUDENT AGREEMENT:}

I represent that my thesis or dissertation and abstract are my original work. Proper attribution has been given to all outside sources. I understand that I am solely responsible for obtaining any needed copyright permissions. I have obtained needed written permission statement(s) from the owner(s) of each third-party copyrighted matter to be included in my work, allowing electronic distribution (if such use is not permitted by the fair use doctrine) which will be submitted to UKnowledge as Additional File.

I hereby grant to The University of Kentucky and its agents the irrevocable, non-exclusive, and royalty-free license to archive and make accessible my work in whole or in part in all forms of media, now or hereafter known. I agree that the document mentioned above may be made available immediately for worldwide access unless an embargo applies.

I retain all other ownership rights to the copyright of my work. I also retain the right to use in future works (such as articles or books) all or part of my work. I understand that I am free to register the copyright to my work.

\section{REVIEW, APPROVAL AND ACCEPTANCE}

The document mentioned above has been reviewed and accepted by the student's advisor, on behalf of the advisory committee, and by the Director of Graduate Studies (DGS), on behalf of the program; we verify that this is the final, approved version of the student's thesis including all changes required by the advisory committee. The undersigned agree to abide by the statements above.

Ilyssa P. Salomon, Student

Dr. Christia Spears Brown, Major Professor

Dr. Mark Fillmore, Director of Graduate Studies 
The Selfie Generation: Examining the Relationship Between Social Media Use and Early Adolescent Body Image

\title{
THESIS
}

A thesis submitted in partial fulfillment of the

Requirements for the degree of Master of Science in the

College of Arts and Sciences

At the University of Kentucky

\author{
By \\ Ilyssa Paige Salomon \\ Lexington, KY \\ Director: Dr. Christia Spears Brown, Professor of Psychology \\ Lexington, KY \\ 2017 \\ Copyright (C) Ilyssa Paige Salomon 2017
}




\begin{abstract}
OF THESIS
THE SELFIE GENERATION: EXAMINING THE RELATIONSHIP BETWEEN SOCIAL MEDIA USE AND EARLY ADOLESCENT BODY IMAGE
\end{abstract}

Social media use among adolescents continues to increase each year. This study explored how the amount of time spent using social media and the specific behaviors used on social media, namely behaviors that involve self-objectification, were related to early adolescents' body image (i.e., body shame and body surveillance). Three types of social media popular among adolescents were examined: Twitter, Facebook, and Instagram. The current study also examined whether certain youth are more at risk for negative body image outcomes than others, by assessing whether adolescents who are particularly focused on others for approval (i.e. high selfmonitors) show greater decrements in body image with greater social media use compared to other adolescents. Results indicated that frequency of social media use predicted higher levels of body shame among individuals high in self-monitoring, and that engagement in selfobjectification behaviors on social media predicted higher levels of body surveillance among early adolescents. Implications of these findings are discussed.

KEYWORDS: Social Media, Body Image, Early Adolescents, Self-Objectification, SelfMonitoring

Ilyssa P. Salomon

Student Signature

4/27/2017

Date 
THE SELFIE GENERATION: EXAMINING THE RELATIONSHIP BETWEEN SOCIAL MEDIA USE AND EARLY ADOLESCENT BODY IMAGE

By

Ilyssa Paige Salomon

Dr. Christia Spears Brown

Director of Thesis

Dr. Mark Fillmore

Director of Graduate Studies

$4 / 27 / 2017$ 
To Mom and Dad,

For always putting my education first. 


\section{ACKNOWLEDGEMENTS}

This thesis not only represents my dedication to academic scholarship, but also the dedication of important individuals who offered me tremendous help and guidance along the way. To my parents, my biggest fans, thank you for always putting my education before everything, and making countless sacrifices to get me where I am today. To my emotional support system, Alex, Ana, Andrew, Tyler, Sam, Stefanie, and Yasmine, thank you for every helpful word and vent-session along the way, and thank you in advance for those in the future. To Dr. Rachel Farr and Dr. Jazmin Brown-Iannuzzi, thank you so much for serving on my thesis committee, and always going above and beyond. Your feedback was an invaluable part of this process, and even with your busy schedules, you both offered the attention to detail and care you would your own students. To the UK Psychology Department and Staff, thank you for providing such a fun and supportive environment for us all to learn and grow in. Finally, to my research mentor, Dr. Christia Spears Brown, I would not be here without your guidance and dedication, and I am eternally grateful. Thank you for your genuine kindness, your advice, your patience, your diligence, and your ability to frame a paper like no other. 


\section{TABLE OF CONTENTS}

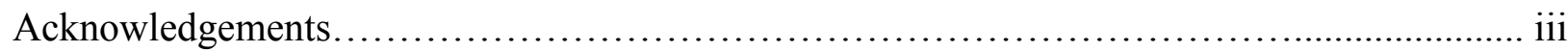

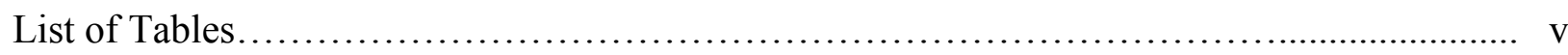

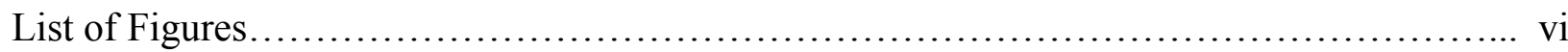

Chapter 1: Introduction

Background and Significance................................................... 1

Social Media and Development.......................................... 2

Social Media and Body Image................................................ 5

Individuals at Risk ....................................................... 8

Current Study and Hypotheses................................................... 10

Chapter 2: Methods

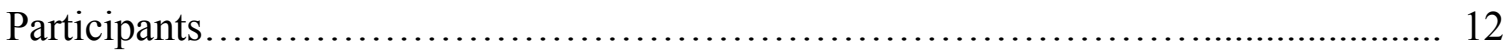

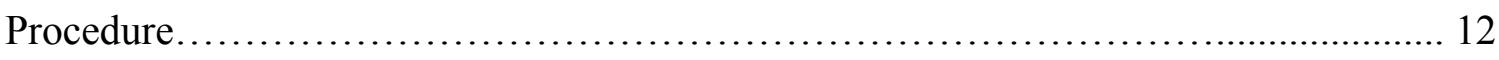

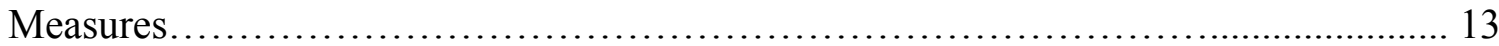

Chapter 3: Results

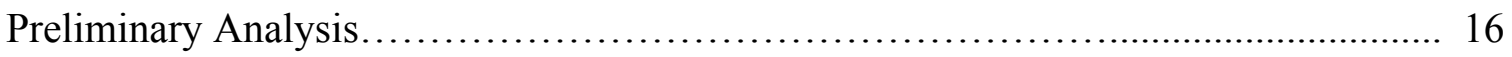

Descriptive Analysis of Social Media Use............................................ 16

Relationship Between Social Media Use and Body Image........................................ 17

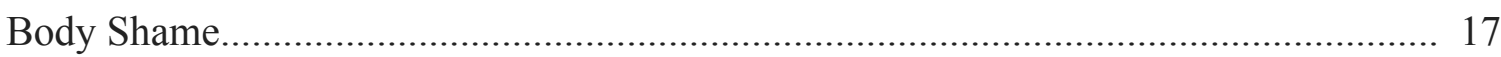

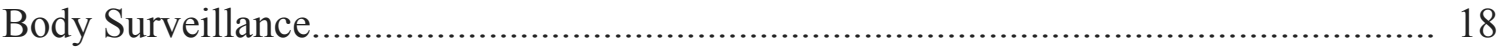

Chapter 4: Discussion

Summary and Contributions of the Current Study ................................... 23

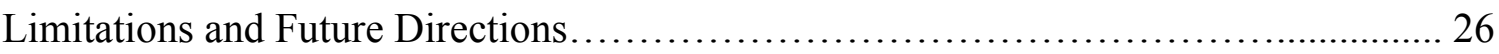

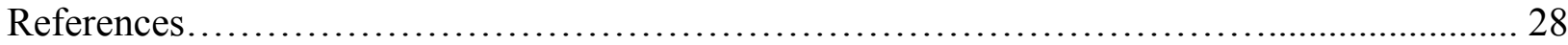

Appendices

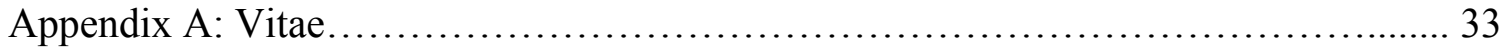




\section{LIST OF TABLES}

Table 1: Means, Standard Deviations, and Correlations Between Variables............................. 19

Table 2: OLS regression of adolescents' body shame, individual-level variables, and interactions.

Table 3: OLS regression of adolescents' body surveillance, individual-level variables,

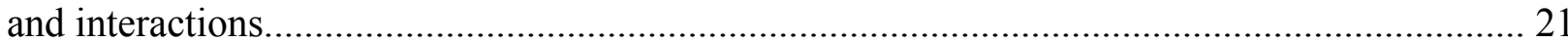




\section{LIST OF FIGURES}

Figure 1: Graph of the interaction between frequency of social media use and

self-monitoring in predicting bod shame........................................................................ 22 


\section{Chapter 1 \\ INTRODUCTION}

\section{Background and Significance}

Early adolescence represents a period of vast developmental changes that span across the physical, psychological, and social dimensions of an individual. Early adolescence is characterized by increases in the importance of peers (Harter, 1999), the tendency to engage in

social comparison (Martin \& Kennedy, 1993), and the importance of physical appearance to selfworth (Harter, 1990) - all of which can increase youth's vulnerability to negative body image (Clay, Vignoles, \& Dittmar, 2005; Harter, 1999; Jones, 2001). Body image is generally defined as the degree to which individuals feel satisfied about their physical selves, which can include body shape, size, and appearance (Cash \& Deagle, 1997). Further, these developmental changes all occur within a cultural context; for children in the US, that context includes heavy exposure to traditional and social media. For example, in recent years, social media use among adolescents has increased rapidly, and $92 \%$ of teens in the US (13-17) report going online daily, with $24 \%$ describing being online or on the Internet "almost constantly" (Lenhart et al., 2015). Because media consistently depicts a very specific and unrealistic body standard, this cultural context can further exacerbate early adolescents' risk of developing negative body image (McKinley \& Hyde, 1996). Together, the notable developmental changes that occur during early adolescence and the ubiquitous nature of social media as a cultural phenomenon suggest it is important to examine how using social media relates to body image among early adolescents. That is the focus of the current study.

The current study explored whether the amount of time spent using social media and the specific behaviors used on social media, namely behaviors that involve self-objectification, are 
related adolescents' body image (i.e., body shame and body surveillance). To capture a range of social media exposure, three types of social media popular among adolescents was examined: Twitter, Facebook, and Instagram. The current study also examines whether certain youth are more at risk for negative body image outcomes than others, by assessing whether adolescents who are particularly focused on others for approval (i.e. high self-monitors) show greater decrements in body image with greater social media use compared to other adolescents.

\section{Social Media and Development}

Several well-established theories within psychology and sociology argue that mass media, particularly media that involves high levels of consumer engagement, is extremely influential in shaping individuals' beliefs and behavior. Theories of social change and human development (Greenfield, 2009) suggest that a shift toward a more Gesellschaft (urbanized) environment is accompanied by an increase in technological development. These technological developments prompt cultural changes, such as an increase in valuing formal education and the acquisition of commerce and wealth, which can in turn shift developmental trajectories (Greenfield, 2009). Currently, the frequent amount of time early adolescents engage with social media in the United States highlights a salient technologically driven cultural change that likely impacts development.

Social cognitive theory of mass communication (Bandura, 2001) also articulates the important role of mass media in shaping individuals' cognitions and behaviors. Social cognitive theory stresses the importance of human agency and observational learning in understanding human behavior (Bandura, 2001). According to this theory, humans form cultural symbols, which communicate information about important values and appropriate behaviors. The media serves as one of our most salient cultural symbols, and individuals learn from these media 
symbols and emulate what they see when determining their own thoughts and behavior, even when it is unintentional (Bandura, 2001). This becomes particularly relevant when thinking about social media, as it differs from conventional forms of media (i.e. television, magazines) in its structure and function.

While social cognitive theory (Bandura, 2001) suggests that media use is never passive, using social media involves active engagement in a more literal sense than conventional media. Elements of social media, defined here as participation in one or more social networking sites, date back to the initial stages of the Internet. However, few of the earlier mediums encompassed all the features associated with modern social media. Boyd and Ellison (2007) define social networking sites as:

Web-based services that allow individuals to (1) construct a public or semi-public profile within a bounded system, (2) articulate a list of other users with whom they share a connection, and (3) view and traverse their list of connections and those made by others within the system (Boyd \& Ellison, 2007).

Of US teens online, $89 \%$ report using at least one social media platform, such as Facebook, Instagram, Snapchat, Twitter, Google+, Tumblr, and Vine (Lenhart et al., 2015). On social media, users can engage in a number of different behaviors and can construct an image of themselves for public display. While previous research suggests that people portray themselves differently on different social media platforms (i.e. what a teen posts on Twitter may differ from what that teen posts on Facebook) (Marwick \& Boyd, 2011), the behaviors available on each type of social media are generally similar. The current study focused on three forms of social media that are currently popular among early adolescents: Facebook, Instagram, and Twitter, all of which meet the criteria for Boyd and Ellison's (2007) definition of social networking sites. 
Facebook, largely considered the prototypical form of social media in 2017 (Davenport, Bergman, Bergman, \& Fearrington, 2014), facilitates interactions between the user and a community of "friends". The official mission statement of Facebook suggests that, "People use Facebook to stay connected with friends and family, to discover what's going on in the world, and to share and express what matters to them" (Facebook 'About', 2017). Twitter is a form of microblogging, and allows users to post up to 140 characters of written content, known as a "Tweet". Instagram capitalizes on the visual aspect of social media through the posting and sharing of photos or videos and interacting with visual content posted by others. While these three social media platforms are different, they allow users to engage in many similar behaviors, such as choosing which content will appear in their newsfeed (collection of information they see upon logging in), posting photos, posting written content, "liking" or commenting on content posted by others, and sending personal messages to other users. As many adolescents report maintaining profiles on several types of social media at a time (Lenhart et al., 2015), the current study focuses on photo behaviors that are common across Facebook, Instagram, and Twitter.

The ability to share images on social media gives users the opportunity to post photos with the goal of receiving positive feedback (i.e., "likes"), and when the photo is of themselves, to receive feedback and reinforcement on their physical appearance. Adolescents can also control the amount of feedback they receive by how much content they post. In addition to providing users with an interactive and reinforcing component not present in conventional forms of media, social media also differs in its representation of personal connections. Specifically, social media networks often represent both individuals from a person's real life (such as friends, family, acquaintances) and cultural figures (such as celebrities and athletes). This seamless integration of real-life peers and idealized celebrities may make it difficult for adolescents to disentangle what 
is idealized and what is attainable. Thus, as social media introduces a number of contextual factors and behaviors not present in conventional forms of media, it becomes important to explore how using social media might affect body image outcomes for early adolescents.

\section{Social Media and Body Image}

During puberty, as sexuality becomes more salient, the perception of one's own physical appearance becomes increasingly important to self-worth (Harter, 1990). In addition to stress induced by normative physical changes, the mass media also plays a critical role in setting cultural standards for ideal body types, which are often unrealistic and emphasize the importance of thinness for girls and muscularity for boys (Swami et al., 2010). When the media sets the bar too high for most youth to reach, it can feel like a personal failure to those who try, which can contribute to negative body image (McKinley \& Hyde, 1996). Links between conventional forms of media and negative body image are well established in the literature among both adolescent girls (Botta, 1999; Harrison \& Hefner, 2006) and boys (Mulgrew, Volcevski-Kostas, \& Rendell, 2014). More recent studies have explored these links on various forms of social media, and found similar results across Western cultures (Manago, Ward, Lemm, Reed, \& Seabrook, 2015; Tiggemann \& Miller, 2010; Tiggemenn \& Slater, 2013; Vandenbosch \& Eggermont, 2013).

The current study examined two aspects of body image: body shame and body surveillance. Body shame can involve both negative feelings toward the body, such as hating certain parts of the body, and negative feelings toward the self, such as feeling weak for failing to achieve the ideal body type (McKinley \& Hyde, 1996). Body surveillance involves an excessive monitoring of the outer appearance, a behavioral consequence of internalizing consistent experiences of objectification (Fredrickson \& Roberts, 1997). Although body shame and surveillance are often conceptualized as part of an overall construct known as objectified 
body consciousness (McKinley \& Hyde, 1996), previous research suggests there is also value in examining the two constructs as separate components of body image (Manago et al., 2015; Moradi \& Huang, 2008). Overall, it is important to distinguish what aspects of social media use may contribute to both body shame and body surveillance in different ways.

When adolescents interact with social media, it is likely they see content from people they know in real life, as well as cultural figures like celebrities. In Westernized societies, celebrities already embody an idealized appearance and further reinforce cultural standards of beauty. However, on social media, even peers have the ability to manipulate photos and engage in tightly-controlled impression management to promote a certain image. Manago and colleagues found that college students on Myspace, a popular social networking site at the time, presented idealized versions of themselves on their profiles, such as photos edited to make themselves look better (Manago, Graham, Greenfield, \& Salimkhan, 2008). For many adolescents, this seamless integration of celebrities and idealized versions of real-life peers, which is unique to social media, presents a ripe environment for upward social comparison, or comparing the self to someone who is "better" in some respect. Social comparisons are especially influential when the subject of comparison is similar and viewed as relevant to the self, such as viewing pictures of peers (Festinger, 1954; Lockwood \& Kunda, 2007). Opinions of peers also grow in importance across adolescence, and individuals are likely to look to others to guide social behavior (Harter, 1999).

Upward social comparisons can lead to negative self-evaluation, particularly when the basis for comparison is important to an individual's self-worth, as is the case with physical appearance (Lockwood \& Kunda, 2007). Thus, consistent exposure to idealized images of peers and cultural figures on social media may increase the risk of experiencing body shame. Previous 
research suggests that adolescents do engage in appearance-based upward social comparisons on social media, and individuals had more negative feelings toward their own bodies after viewing social media profiles of attractive users versus unattractive users (Haferkamp \& Kramer, 2011). This upward social comparison is not limited to appearance, and one study found that the longer individuals had used Facebook, the more they felt that other people were happier than them and that life overall was unfair (Chou \& Edge, 2012). Taken together, evidence suggests that the nature of social media sets the stage for social comparison processes to occur, which may contribute to negative body image among early adolescents.

Certain specific behaviors on social media may also contribute to the development of negative body image. Objectification theory (Fredrickson \& Roberts, 1997) suggests that women internalize consistent experiences of sexual objectification, defined as "the experience of being treated as a body (or collection of body parts) valued predominately for its use to (or consumption by) others" (1997, pg. 174). This internalization can result in excessive monitoring of the body's outward appearance by taking another's perspective, also referred to as body surveillance. Self-objectification occurs when individuals consistently value a third-person perspective of their body over their own personal perspective (Fredrickson \& Roberts, 1997). In addition to detriments in motivation and performance, the tendency to self-objectify and engage in body surveillance reflects the internalization of cultural body standards and can further increase the risk of experiencing body shame and other negative outcomes (Noll \& Fredrickson, 1998).

Behaviors that promote self-objectification, or adopting a third-person perspective toward the self, are common on social media. Such behaviors include posting "selfies" (photos one takes of oneself) and asking others to rate one's looks. The act of taking and posting photos of oneself 
on social media serves as a form of self-objectification and reinforces focusing on the body as an object for consumption. Previous evidence suggests that people post on social media with their network of friends in mind, which may further encourage experiencing the body from an outside perspective (Manago et al., 2008). In two separate samples of adolescent girls in Australia, time spent using Myspace and Facebook, and likely engaging in forms of self-objectification, predicted body surveillance, internalization of thin ideals, and drive for thinness (Tiggemann \& Miller, 2010; Tiggemann \& Slater, 2013). Similarly, in a sample of college-aged men and women in the US, involvement in Facebook predicted higher levels of body surveillance, which further predicted body shame (Manago, Ward, Lemm, Reed, \& Seabrook, 2015). Other research has focused more specifically on actual behaviors on social media and found that the amount of time adolescent girls spent on photo activities on Facebook, not just the amount of time on Facebook overall, predicted the internalization of thin ideals, self-objectification, dissatisfaction with weight, and drive for thinness (Meier \& Gray, 2014).

Taken together, previous research suggests that it is important to understand not only how frequently adolescents use social media, but also what specific behaviors they may engage in that could contribute to negative body image. While many studies exploring links between certain types of social media use have focused specifically on behaviors within one platform (i.e. Facebook or Myspace), the nature and popularity of a specific type of social media can change rapidly. Thus, the current study extended current findings by generalizing common behaviors that are available across three popular types of social media. It was hypothesized that not only time spent using social media, but also the degree to which early adolescents engage in selfobjectification behaviors, would predict higher body surveillance and body shame. 


\section{Individuals at Risk}

There are two factors that may relate to the relationship between social media use and body image: individuals' gender and the degree to which they engage in self-monitoring. First, boys and girls may differ in overall social media use and body image. Although negative body image is often characterized as an issue only relevant to women, evidence suggests men are also vulnerable to the influence of popular media on body image. The sexualization of men in the media has increased in recent years, and evidence suggests men can also experience the negative consequences of objectification usually equated with women living in westernized societies (Rohlinger, 2002; Michaels, Parent, \& Moradi, 2013). Many studies examining links between social media use and objectified body consciousness (which includes both body surveillance and body shame) have found negative effects for both men and women in adolescent and adult samples (Manago et al., 2015; Slater \& Tiggemann, 2010). Thus, because social media use is so common among adolescents, it is important to include both boys and girls when examining the impact of social media use on body image. However, based on previous research that demonstrated higher levels of negative body image among adolescent girls (Slater \& Tiggemann, 2010), it was hypothesized that girls would have higher levels of body shame and body surveillance than boys overall.

Second, the degree to which adolescents engage in self-monitoring may moderate the relationship between social media and body image. The human relationship with media is reciprocal, in that people will seek out media that appeals to them, which can further reinforce certain thoughts and behavior (Levine \& Harrison, 2009). Thus, individual differences among adolescents will affect how they use social media, and some adolescents may be more likely to engage in upward social comparison and objectify themselves on social media than others. Self- 
monitoring represents an individual difference that may place certain adolescents at risk of interacting with social media in ways that can exacerbate negative body image. An individual's level of self-monitoring refers to a sensitivity to social cues and a willingness to react to them (Snyder, 1987). This involves not only looking to others as a way to gauge appropriate behavior, but also choosing actions that portray the self in a particular light based on that appraisal. Evidence suggests that people high in self-monitoring are more susceptible to peer pressure, and more easily swayed by the thoughts and actions of others (Perrine \& Aloise-Young, 2004; Prislin $\&$ Kovrlija, 1992). Thus, adolescents with a higher tendency to self-monitor and seek approval from others may be hypersensitive to cultural ideals perpetuated by social media, and thus more vulnerable to experiencing body surveillance and body shame. It was hypothesized that the relationship between social media use and negative body image would be exacerbated among high self-monitoring adolescents relative to low self-monitoring adolescents.

\section{Current Study and Hypotheses}

The current study explored how the frequency of overall social media use and the frequency of specific self-objectification behaviors on social media predicted adolescents' body image. It was hypothesized that more frequent use of social media and greater engagement in more self-objectification behaviors (e.g., posting pictures of the self) would predict negative outcomes in both body shame and body surveillance. It was hypothesized that these behaviors would differ by gender, with girls experiencing higher body shame and surveillance overall. The current study also examined whether certain youth are more at risk for negative body image outcomes than others, by examining whether adolescents who are particularly focused on others for approval (i.e., high self-monitors) show greater decrements in body image compared to other adolescents. Specifically, it was predicted that self-monitoring would moderate the relationships 
between social media use, self-objectification, and body image, such that the relationship would be stronger among individuals who are high (compared to low) on self-monitoring. 


\section{Chapter 2}

\section{METHOD}

\section{Participants}

Participants were 142 seventh grade students from four public middle schools in a medium-sized city in the Upper South (population approximately 300,000). The sample consisted of 43 boys and 99 girls, with a mean age of 12.44 years $(S D=.61)$. Data collection was approved by the authors' university Institutional Review Board (IRB) and permitted by principals at each school. Across all four schools, average enrollment during the 2015-2016 school year was 662 students. Our sample demonstrated considerable ethnic and socioeconomic diversity. Although nearly half of all participants identified as White/European American (45\%), sizable portions of our sample reported being Latina/Hispanic (22\%), Black/African American (19\%), and multiracial (most of which identified as Black/White and Latina/White; 13\%). The remainder of our sample identified as Asian (1\%). All middle schools also reported having at least half of their students on free or reduced lunch, with a range of $49-85 \%$ of students qualifying for assistance. The racial/ethnic composition of participants from each school was largely representative of the school's racial/ethnic composition as a whole.

\section{Procedure}

As part of a larger study, participants were recruited through visits to the four participating middle schools. All seventh grade students were given parental consent forms to take home. To incentivize participants to return these forms, all students who returned signed consent forms - regardless of parental approval or disapproval of participation-were entered into a drawing for a \$50 Amazon gift card. Consent rates were low at some of the schools, ranging from $15-53 \%$ across schools. Importantly, consent rates were consistent with the 
expectations of the principals, who noted their own difficulties with getting forms signed and returned. Very few parents actively declined participation (and low consent rates seemed to be driven by students failing to return signed forms). Those students with parental consent were then asked to sign an assent form before they completed the survey. Only students with a signed consent and assent form were allowed to take the survey. All testing took place during one class period on two separate days. Participants had the whole class time (approximately 50 minutes) each day to complete the survey.

\section{Measures}

Demographics. The demographic information collected from participants included gender, age, and ethnicity. Participants also reported their number of siblings, gender of siblings, parent education level, and parent occupation.

Frequency of Social Media Use. To assess time spent using social media, participants indicated whether or not they had accounts on certain social media websites or mobile applications (Instagram, Facebook, Twitter, and Tumblr) and how many hours they spend on each site in a typical week $(0,1-3,4-6,7-9,10+)$. Each range of hours on the scale was assigned a score, $0=0,1-3=1,4-6=2,7-9=3$, and $10+=4$. Only ten students used Tumblr, so it was not included in analyses. For this study, we summed the scores for time participants spent on Instagram, Facebook, and Twitter. Scores could range from 0 (indicating no time on social media in a typical week) to 12 (indicating a score of 4 on each scale, or 10+ hours a week across all three included platforms).

Self-Objectification Behaviors on Social Media. To assess engagement in selfobjectification behaviors on social media, participants filled out a checklist indicating what they post about on social media. Self-objectification behaviors were defined as behaviors on social 
media that likely involve thinking about the body or self from a third-person perspective. The checklist included 10 types of posts overall, six of which we defined as self-objectification behaviors, which included: "Asking for people to rate me or a photo of me", "Pictures of me", "Pictures of me with other people", "Selfies of face only", "Selfies of body and face", "Selfies of body with no face". For this study, we summed the amount of self-objectification behaviors participants engaged in for an overall score. Scores could range from 0 (indicating no selfobjectification behaviors) to 6 (indicating engaging in all six types of self-objectification behavior).

Body Image. Participants completed two subscales, body shame and body surveillance, from the youth version of the Objectified Body Consciousness Scale (OBCS) developed by Lindberg, Hyde, and McKinley (2006). Items from the body surveillance subscale include, "I often compare how I look with how other people look" and "During the day, I think about how I look many times". Items from the body shame subscale include, "I feel ashamed of myself when I haven't made an effort to look my best" and "I feel like I must be a bad person when I don’t look as good as I could". Participants were asked to indicate the level to which they agreed with each item on a Likert scale $(1=$ disagree strongly, $2=$ disagree somewhat, $3=$ agree somewhat, 4 $=$ strongly agree). Both of the subscales had good psychometric qualities (body shame $\alpha=0.77$, body surveillance $\alpha=0.82$ ).

Self-Monitoring. Participants filled out a modified version of the Junior Self-Monitoring Scale by Graziano, Leone, Musser, and Lautenschlager (1987). This measure captures adolescents' tendencies to self-monitor, or look to social cues from others to guide behavior. The 19 items include, "I sometimes wear some kinds of clothes just because my friends are wearing that kind" and "I act better when my teacher is in the room than when my teacher is out of the 
room". Participants indicated how much each item was true for them by responding to each item on a Likert scale $(1=$ Not at all true, $2=A$ little true, $3=$ Somewhat true, $4=$ Often true $)$. The measure has good psychometric qualities $(\alpha=.78)$. 


\section{Chapter 3}

\section{RESULTS}

\section{Preliminary Analyses}

Bivariate correlations, means, and standard deviations for each variable are presented in Table 1. The results of a series of one-way analyses of variance indicated there were no differences based on ethnicity in social media use, self-monitoring, body shame, body surveillance, or self-objectification behaviors on social media. A series of one-way analyses of variance also indicated that there were no gender differences in frequency of social media use, self-monitoring, body shame, or body surveillance. However, girls did engage in significantly more self-objectification behaviors on social media than boys, $F(1,128)=7.50, p<.01$.

\section{Descriptive Analysis of Social Media Use}

Overall, $79.9 \%$ of the sample had at least one social media account (excluding missing data from eight participants). For girls, 71.7\% had Instagram accounts, 46.5\% had Facebook accounts, and $14.1 \%$ had Twitter accounts. For boys, $62.8 \%$ had Instagram accounts, 51.2\% had Facebook accounts, and 25.6\% had Twitter accounts. For frequency of social media use, participants reported a mean score of $2.14(S D=5.40)$, which is approximately 4-6 hours using social media each week. Overall, participants reported engaging in a mean of $2.34(S D=1.56)$ self-objectification behaviors on social media. Of the six self-objectification behaviors, $11.3 \%$ of the sample reported "Asking for people to rate me or a photo of me" $(14 \%$ of girls and $8 \%$ of boys, $n . s$. gender difference), $52.1 \%$ reported posting "Pictures of me" (63\% of girls and $40 \%$ of boys, $\left.X^{2}=5.66, p<.05\right), 61.3 \%$ reported posting "Pictures of me with other people" (74\% of girls and $48 \%$ of boys, $\left.X^{2}=7.80, p<.005\right), 49.3 \%$ reported posting "Selfies of face only" $(59 \%$ of girls and $42 \%$ of boys, n.s. gender difference), $38.0 \%$ reported posting "Selfies of body and 
face" ( $45 \%$ of girls and $33 \%$ of boys, n.s. gender difference), and $0.7 \%$ reported posting "Selfies of body with no face" (only 1 girl total).

\section{Relationship Between Social Media Use and Body Image}

To assess the primary hypotheses, we used SPSS to run two OLS regression models predicting participants' (a) body shame and (b) body surveillance. The main effect variables entered into each model included gender, self-monitoring, frequency of social media use, and self-objectification behaviors on social media. To examine whether each social media variable was moderated by self-monitoring, two interaction terms were entered into the models: the interaction between self-monitoring and frequency of social media use and the interaction between self-monitoring and objectification behaviors. All of the variables entered into the regression models were mean-centered. The results of each regression model are shown in Tables 2 and 3 .

\section{Body Shame}

Results indicated that the model accounted for a significant amount of variance in body shame, $F(6,87)=6.204, R^{2}=.30, p<.001$. Specifically, higher levels of self-monitoring were a significant predictor of higher levels of body shame, $\beta=.51, p<.001$. As hypothesized, there was also a significant interaction between self-monitoring and frequency of social media use, $\beta=$ $.21, p<.05$. Simple slope analysis using PROCESS macro (Hayes, 2012) indicated that social media use was associated with an increase in body shame for high (1 SD above the mean) selfmonitors, $b=.10, t(98)=-2.48, p<.05$ (see Figure 1 ). There was no significant association between social media use and body shame for average self-monitors, $b=.02, t(98)=. .87, p>$ .05 , or low (1 SD below the mean) self-monitors, $b=-.05, t(98)=-1.09, p>.05$. Gender, 
objectification behaviors, and the interaction between self-monitoring and objectification behaviors were not significant predictors of body shame (see Table 2).

\section{Body Surveillance}

Results indicated that the model accounted for a significant amount of variance in body surveillance, $F(6,87)=7.817, R^{2}=.35, p<.001$. Similar to the model predicting body shame, higher levels of self-monitoring were a significant predictor of higher levels of body surveillance, $\beta=.55, p<.001$. As hypothesized, higher levels of objectification behaviors on social media were a significant predictor of higher body surveillance, $\beta=.24, p<.05$. Specifically, early adolescents who engaged in more objectification behaviors (i.e., positing pictures of themselves) reported higher levels of body surveillance. Gender, frequency of social media use, and the interaction terms between self-monitoring, frequency of social media use, and objectification behaviors were not significant predictors of body shame (see Table 3). 
Table 1

Means, Standard Deviations, and Correlations Between Variables

\begin{tabular}{lcccccc}
\hline Measure & $\mathrm{M}(\mathrm{SD})$ & 1 & 2 & 3 & 4 & 5 \\
\hline 1. Frequency of Social Media & $2.14(2.12)$ & - & $.42^{* *}$ & $.24^{*}$ & $.23^{*}$ & .14 \\
2. Self-Objectification Behaviors & $2.34(1.56)$ & - & - & .13 & .15 & $.23^{* *}$ \\
3. Self-Monitoring & $2.24(.45)$ & - & - & - & $.50^{* *}$ & $.63^{* *}$ \\
4. Body Shame & $1.66(.66)$ & - & - & - & - & $.58^{* *}$ \\
5. Body Surveillance & $2.18(.86)$ & - & - & - & - & - \\
\hline
\end{tabular}

Note: $* p<.05, * * p<.001$. 
Table 2

OLS regression of adolescents' body shame, individual-level variables, and interactions.

\begin{tabular}{lccccc}
\hline & $\mathrm{B}$ & Std. Error & Beta & $\mathrm{t}$ & Sig ( $p$ value $)$ \\
\hline Independent Variables & & & & & \\
Gender & .01 & .13 & .01 & .07 & .945 \\
Self-Monitoring & .75 & .14 & .51 & 5.27 & .000 \\
Frequency of Social Media Use & .02 & .03 & .07 & .71 & .481 \\
Objectification Behaviors & .02 & .04 & .05 & .50 & .615 \\
Self-Monitoring X Frequency & .19 & .09 & .21 & 2.01 & .048 \\
Self-Monitoring X Objectification & -.02 & .10 & -.03 & -.24 & .810 \\
\hline
\end{tabular}

Model F(6,87) $=6.20, p<.001$

$\mathrm{R}^{2}=.30$ 
Table 3

OLS regression of adolescents' body surveillance, individual-level variables, and interactions.

\begin{tabular}{lccccc}
\hline & $\mathrm{B}$ & Std. Error & Beta & $\mathrm{t}$ & Sig $(p$ value $)$ \\
\hline Independent Variables & & & & & \\
Gender & .18 & .17 & .10 & 1.12 & .267 \\
Self-Monitoring & 1.05 & .18 & .55 & 5.92 & .000 \\
Frequency of Social Media Use & -.04 & .04 & -.10 & -1.04 & .303 \\
Objectification Behaviors & .13 & .05 & .24 & 2.49 & .015 \\
Self-Monitoring X Frequency & .04 & .12 & .04 & .37 & .712 \\
Self-Monitoring X Objectification & .06 & .13 & .05 & .47 & .641 \\
\hline
\end{tabular}

Model F(6,87) $=6.20, p<.001$

$\mathrm{R}^{2}=.35$ 


\section{Figure 1}

Graph of the interaction between frequency of social media use and self-monitoring in predicting body shame.

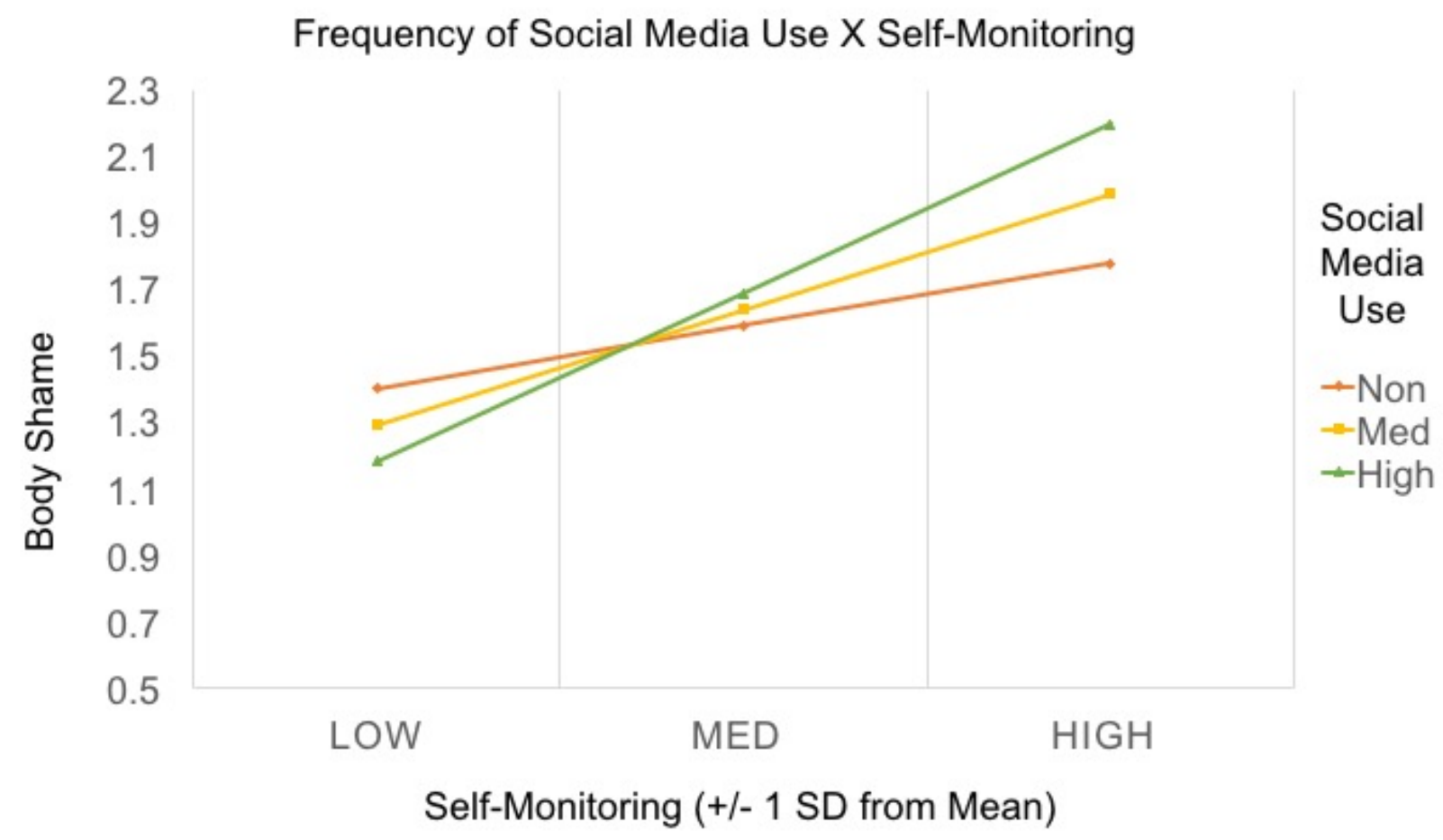




\section{Chapter 4}

\section{DISCUSSION}

The current study investigated how social media use is related to adolescent body image among a sample of early adolescents. Specifically, the study examined both the frequency of social media use on three popular platforms (Twitter, Instagram, and Facebook) and selfobjectification behaviors on social media as predictors of body shame and body surveillance. The current study also explored the moderating role of an early adolescents' level of self-monitoring, or the tendency to look to others for approval, in predicting adolescent body image. In general, the results supported the hypotheses, suggesting that both frequency of social media use and engaging in self-objectification behaviors on social media predicted negative consequences for body shame and body surveillance for some individuals. The results also indicated that an individual's level of self-monitoring moderates how social media use is related to body image.

Overall, approximately $80 \%$ of the sample of seventh graders had at least one social media account on Twitter, Instagram, or Facebook. On average, participants reported using social media 4-6 hours each week. Participants also reported engaging in slightly more than two types of self-objectification behaviors on average, with girls engaging in more selfobjectification than boys. Specifically, the majority of girls (3 out of 4) and half of the boys posted pictures of themselves with other people. Approximately half of the sample posted pictures of themselves alone or of their face specifically. Despite public concerns, only one participant (a girl) posted a picture of just her body.

For frequency of social media use, the results indicated that more time spent using social media predicted higher levels of body shame among adolescents, but only for individuals high in self-monitoring. In other words, for individuals that are more likely to look to others for 
approval, they felt worse about their bodies the more time they spent on social media. This body shame can take the form of either shame toward specific parts of the body, or shame toward the self for not achieving the ideal body type. By definition, high self-monitors are more sensitive to social cues and more willing to change their behavior based on the interpretation of those cues. This tendency to look outward for guidance and approval may introduce a vulnerability to the body standards perpetuated by culture. During puberty, when appearance becomes more central to self-worth, early adolescents high in self-monitoring may be looking outward for an understanding of how attractive bodies ought to look, and trying to adjust accordingly. However, cultural body standards (i.e. thinness for girls, muscularity for boys) are impossible for most people to achieve, and the failure to meet them can elicit body shame. The majority of social media involves image sharing, and these images often contain idealized and flattering photos of celebrities, cultural figures, and peers. Early adolescents high in self-monitoring may be more likely to compare themselves to these idealized images in an attempt to guide their image and behavior, resulting in the internalization of cultural body standards. At the very least, the results suggest that, when high self-monitors are engaging with social media, they are at a higher risk for experiencing body shame.

Regarding self-objectification behaviors, the current study also found that engaging in self-objectification behaviors on social media predicted higher levels of body surveillance, or excessive monitoring of the body's outer appearance. Specifically, early adolescents who reported posting different types of selfies, photos of themselves, and asking people to rate them on social media had higher levels of body surveillance than adolescents who posted fewer photos of themselves, over and above the amount of time they spent on social media. Behaviors that promote self-objectification, or adopting and valuing a third-person perspective toward the self, 
are common on social media. Previous evidence suggests that people indeed post on social media with their audience in mind (Manago et al., 2008), which involves adopting the perspective of the observer. The reinforcing nature of social media allows users to receive feedback on their appearance, and whether this feedback is specifically elicited (by asking followers to rate a photo) or involves simply receiving positive comments or "likes" on a photo, the feedback serves as a form of psychological reward and reinforcement. The current study suggests that the ease and availability of this reinforcement may not only increase the frequency of self-objectification behaviors on social media, but also change how adolescents think about their bodies offline, and is associated with excessive monitoring of how the body looks to others.

The findings of the current study did not support the hypothesized gender differences in body shame and surveillance for boys and girls. Although girls did report engaging in significantly more self-objectification behaviors on social media than boys, gender did not predict body shame or body surveillance. Often, research on body image focuses on the body image concerns of girls, assuming that boys are less impacted by cultural standards of attractiveness (Perloff, 2014). The current findings, however, suggest that greater body shame and greater body surveillance can describe boys as well as girls. Future research efforts should aim to explore whether specific behaviors on social media differentially predict the body image of boys and girls.

The current study also examined individual differences in self-monitoring as a risk factor in experiencing body shame and surveillance. As described above, the frequency of social media use only predicted body shame for individuals high in self-monitoring. For individuals naturally more attuned to what others will think, frequent use of social media seems to increase their vulnerability to feelings of inadequacy in the form of body shame. Self-monitoring, as an 
individual predictor, also accounted for a significant portion of variance in both body shame and surveillance. These findings suggest that high self-monitors seem to think about their bodies more often from an outside perspective, regardless of social media use. Overall, the results of the current study suggest it is important to take individual differences among adolescents into account, as they may place certain individuals at higher risk of engaging with social media in ways that could exacerbate negative body image.

\section{Limitations and Future Directions}

While the findings of the current study shed light on how social media use may be associated with adolescent body image, there are several limitations. The data presented is correlational, and longitudinal data is necessary to draw conclusions about the direction of the observed effects. Cultural pressures on body image begin well before adolescence, and by the time girls are 13, more than half (63.2\%) are afraid of gaining weight (Micali, Ploubidis, De Stavola, Simonoff, \& Treasure, 2014). This suggests that by the time adolescents are engaging with social media, many likely already have negative feelings toward their bodies. Thus, adolescents with preexisting attitudes about their bodies may approach and interpret their experiences on social media in different ways, resulting in different outcomes. Because social media use increases across adolescence (Lenhart, 2015), it will be important for future research to delve deeper into the direction of these effects and examine the influence of social media use on body image over time.

The current study also does not fully capture the rich, complex nature of social media use in its entirety. Social media users can engage in a multitude of behaviors online, and individuals will interpret these experiences in different ways. In an attempt to generalize across behaviors available on a number of popular social media platforms, the current study loses some of the 
detail in all the behaviors available to individuals using specific types of social media. Most notably, previous research (e.g., Davenport, Bergman, Bergman, \& Fearrington, 2014) has looked at differences between passive use (consuming content posted by others) and active use (posting content for others to consume), while the current study only explores a particular type of active use. It will be important for future research to continue exploring the general differences between passive and active use, as well as consequences of specific behaviors within each category.

Finally, the current study only looks at two individual differences among participants: gender and self-monitoring. While gender was not a significant predictor in this particular analysis, it may still play an important role in understanding the relationship between social media use and body image. Future research should investigate gender differences in how adolescents approach social media (i.e. intentions for reading or posting certain content) and how they interpret what they see on social media (i.e. how certain posts make them feel about themselves). Similarly, while the present results supported the role of self-monitoring as a moderator and individual predictor for adolescent body image, future research should further explore how individuals who are high in self-monitoring may interact differently with social media than individuals who are average or low in self-monitoring. Above all, the results of the current study certainly suggest that individual differences will play an important role in understanding the consequences of early adolescent social media use and represents an important area for future research. 


\section{$\underline{\text { References }}$}

Bandura, A. (2001). Social cognitive theory of mass communication. Media psychology, 3(3), 265-299.

Botta, R. A. (1999). Television images and adolescent girls' body image disturbance. Journal of communication, 49(2), 22-41.

Boyd, D., Ellison, N. (2007). Social network sites: Definition, history, and scholarship. Journal of Computer-Mediated Communication, 13(1), 210-230.

Cash, T. F., \& Deagle, E. A. (1997). The nature and extent of body-image disturbances in anorexia nervosa and bulimia nervosa: A meta-analysis. International Journal of Eating Disorders, 22(2), 107-126.

Chou, H. T. G., \& Edge, N. (2012). "They are happier and having better lives than I am": the impact of using Facebook on perceptions of others' lives. Cyberpsychology, Behavior, and Social Networking, 15(2), 117-121.

Clay, D., Vignoles, V. L., \& Dittmar, H. (2005). Body image and self-esteem among adolescent girls: Testing the influence of sociocultural factors. Journal of research on adolescence, 15(4), 451-477.

Davenport, S. W., Bergman, S. M., Bergman, J. Z., \& Fearrington, M. E. (2014). Twitter versus Facebook: Exploring the role of narcissism in the motives and usage of different social media platforms. Computers in Human Behavior, 32, 212-220.

Facebook about.(2017). Retrieved April 27, 2017, from https://www.facebook.com/pg/facebook/about/

Festinger, L. (1954). A theory of social comparison processes. Human relations, 7(2), 117-140. 
Fredrickson, B. L., \& Roberts, T. A. (1997). Objectification theory. Psychology of women quarterly, 21(2), 173-206.

Graziano, W. G., Leone, C., Musser, L. M., \& Lautenschlager, G. J. (1987). Self-monitoring in children: A differential approach to social development. Developmental Psychology, 23(4), 571.

Greenfield, P. M. (2009). Linking social change and developmental change: shifting pathways of human development. Developmental psychology, 45(2), 401.

Haferkamp, N., \& Krämer, N. C. (2011). Social comparison 2.0: Examining the effects of online profiles on social-networking sites. Cyberpsychology, Behavior, and Social Networking, 14(5), 309-314.

Harrison, K., \& Hefner, V. (2006). Media exposure, current and future body ideals, and disordered eating among preadolescent girls: A longitudinal panel study. Journal of Youth and Adolescence, 35(2), 146-156.

Harter, S. (1990). Causes, correlates, and the functional role of global self-worth: A life-span perspective.

Harter, S. (1999). The construction of the self: A developmental perspective. Guilford Press.

Hayes, A. F. (2012). PROCESS: A versatile computational tool for observed variable mediation, moderation, and conditional process modeling.

Jones, D. C. (2001). Social comparison and body image: Attractiveness comparisons to models and peers among adolescent girls and boys. Sex roles, 45(9), 645-664.

Lenhart, A., Duggan, M., Perrin, A., Stepler, R., Rainie, H., \& Parker, K. (2015). Teens, social media \& technology overview 2015. 
Levine, M. P., \& Harrison, K. (2009). Effects of media on eating disorders and body image. Media effects: Advances in theory and research, 490-516.

Lindberg, S. M., Hyde, J. S., \& McKinley, N. M. (2006). A measure of objectified body consciousness for preadolescent and adolescent youth. Psychology of Women Quarterly, 30(1), 65-76.

Lockwood, P., \& Kunda, Z. (1997). Superstars and me: Predicting the impact of role models on the self. Journal of personality and social psychology, 73(1), 91.

Manago, A. M., Graham, M. B., Greenfield, P. M., \& Salimkhan, G. (2008). Selfpresentation and gender on MySpace. Journal of Applied Developmental Psychology, 29(6), 446-458.

Manago, A. M., Ward, L. M., Lemm, K. M., Reed, L., \& Seabrook, R. (2015). Facebook involvement, objectified body consciousness, body shame, and sexual assertiveness in college women and men. Sex roles, 72(1-2), 1-14.

Martin, M. C., \& Kennedy, P. F. (1993). Advertising and social comparison: Consequences for female preadolescents and adolescents. Psychology \& Marketing, 10(6), 513-530.

Marwick, A. E., \& Boyd, D. (2011). I tweet honestly, I tweet passionately: Twitter users, context collapse, and the imagined audience. New media \& society, 13(1), 114-133.

McKinley, N. M., \& Hyde, J. S. (1996). The objectified body consciousness scale development and validation. Psychology of women quarterly, 20(2), 181-215.

Meier, E. P., \& Gray, J. (2014). Facebook photo activity associated with body image disturbance in adolescent girls. Cyberpsychology, Behavior, and Social Networking, 17(4), 199-206. 
Micali, N., Ploubidis, G., De Stavola, B., Simonoff, E., \& Treasure, J. (2014). Frequency and patterns of eating disorder symptoms in early adolescence. Journal of Adolescent Health, 54(5), 574-581.

Michaels, M. S., Parent, M. C., \& Moradi, B. (2013). Does exposure to muscularity-idealizing images have self-objectification consequences for heterosexual and sexual minority men?. Psychology of Men \& Masculinity, 14(2), 175.

Moradi, B., \& Huang, Y. (2008). Objectification theory and psychology of women: A decade of advances and future directions. Psychology of Women Quarterly, 32,377-398.

Mulgrew, K. E., Volcevski-Kostas, D., \& Rendell, P. G. (2014). The effect of music video clips on adolescent boys' body image, mood, and schema activation. Journal of youth and adolescence, 43(1), 92-103.

Noll, S. M., \& Fredrickson, B. L. (1998). A mediational model linking self-objectification, body shame, and disordered eating. Psychology of Women Quarterly, 22(4), 623-636.

Perloff, R. M. (2014). Social media effects on young women's body image concerns: Theoretical perspectives and an agenda for research. Sex Roles, 71(11-12), 363-377.

Perrin, A., \& Duggan, M. (2015). Americans' internet access: 2000-2015. Pew Research Center, 26.

Perrine, N. E., \& Aloise-Young, P. A. (2004). The role of self-monitoring in adolescents' susceptibility to passive peer pressure. Personality and Individual Differences, 37(8), $1701-1716$.

Prislin, R., \& Kovrlija, N. (1992). Predicting behavior of high and low self-monitors: An application of the theory of planned behavior. Psychological Reports, $70(3$ suppl), 11311138. 
Rohlinger, D. A. (2002). Eroticizing men: Cultural influences on advertising and male objectification. Sex roles, 46(3-4), 61-74.

Snyder, M. (1987). Public appearances, private realities: The psychology of self-monitoring. WH Freeman/Times Books/Henry Holt \& Co.

Tiggemann, M., \& Miller, J. (2010). The Internet and adolescent girls' weight satisfaction and drive for thinness. Sex roles, 63(1-2), 79-90.

Tiggemann, M., \& Slater, A. (2013). NetGirls: The Internet, Facebook, and body image concern in adolescent girls. International Journal of Eating Disorders, 46(6), 630-633.

Valkenburg, P. M., Peter, J., \& Schouten, A. P. (2006). Friend networking sites and their relationship to adolescents' well-being and social self-esteem. CyberPsychology \& Behavior, 9(5), 584-590.

Vandenbosch, L., \& Eggermont, S. (2013). Sexualization of adolescent boys: Media exposure and boys' internalization of appearance ideals, self-objectification, and body surveillance. Men and Masculinities, 16(3), 283-306.

Ward, L. M. (2003). Understanding the role of entertainment media in the sexual socialization of American youth: A review of empirical research. Developmental Review, 23(3), 347-388.

Zurbriggen, E. L., Collins, R. L., Lamb, S., Roberts, T. A., Tolman, D. L., Ward, L. M., \& Blake, J. (2007). Report of the APA Task Force on the Sexualization of Girls. American Psychological Association: Washington, DC Available online at http://www.apa.org/pi/wpo/sexualizationrep. pdf. 


\section{Vita}

Ilyssa Salomon

Born in Plantation, FL

\section{$\underline{\text { Education }}$}

B.A. Psychology University of Miami Major: Psychology; Minors: Sociology, English

$\underline{\text { Scholarships, Awards, and Honors }}$

Graduated with honors, cum laude University of Miami Dickinson Scholarship

\section{$\underline{\text { Research Experience }}$}

The University of Kentucky Center for Equality and Social Justice, Research Fellow

Graduate Student, Advisor: Christia Spears Brown, Ph.D.

Project Manager, Principal Investigator: Michael McCullough, Ph.D.

Laboratory Assistant, Principal Investigator: Marc Gellman, Ph.D

Laboratory Assistant, Principal Investigator: Debra Lieberman, Ph.D

\section{$\underline{\text { Research Presentations }}$}

Salomon, I., Brown, C.S. (2017, April). The selfie generation: Examining the relationship between social media use and adolescent body image. Poster will be presented at the Biennial Society for Research in Child Development Conference. Austin, Texas.

Salomon, I., Farr, R., Brown-Iannuzzi, J., Brown, C.S. (2016, October). Children's attitude toward children from same-sex parent families. Poster presented at 7 th Biennial Gender Development Research Conference. San Francisco, California.

\section{Manuscripts Under Review}

Farr, R., Salomon, I., Brown-Iannuzzi, J., Brown, C.S. Elementary School-Age Children's Attitudes toward Children in Same-Sex Parent Families.

\section{$\underline{\text { Manuscripts in Preparation }}$}

Salomon, I., Brown, C.S. (2017, April). The selfie generation: Examining the relationship between social media use and adolescent body image. 


\section{Teaching Experience}

Teaching Assistant, University of Kentucky 2016 Processes of Psychological

Development University of Kentucky

Teaching Assistant, University of Kentucky 2016 Forensic Psychology University of Kentucky

Teaching Assistant, University of Kentucky 2016 Experimental Psychology University of Kentucky

Teaching Assistant, University of Kentucky 2015 Introduction to Psychology University of Kentucky

\section{$\underline{\text { Service }}$}

Chabad UK Graduate Student Representative 2015-present 